\title{
Psychometric study of the Nursing Care Scale for Pain Management
}

Estudo psicométrico da Escala de Práticas de Enfermagem na Gestão da Dor Estudio psicométrico de la Escala de Prácticas de Enfermería en la Gestión del Dolor Catarina André Silva António*iD; Eduardo José Ferreira dos Santos**iD; Madalena Cunha***iD; João Carvalho Duarte ${ }^{* * * *}$ (iD)

\begin{abstract}
Background: Pain is inefficiently managed by nurses in part due to the lack of tools capable of measuring and monitoring such practice.

Objective: To assess the psychometric properties of the Nursing Care Scale for Pain Management.

Methodology: This descriptive correlational study assessed internal consistency using Cronbach's alpha coefficient and confirmatory factor analysis using the covariance matrix - maximum likelihood algorithm.

Results: The study involved 260 nurses with a mean age of 35.42 years, $78.5 \%$ of whom were women. After the refinement of the scale, the overall internal consistency was $\alpha=0.95$, and the score by factors was: initial assessment $\alpha=0.85$; Planning $\alpha=0.76$; Implementation of non-pharmacological interventions $\alpha=0.80$; Educating the person with pain $\alpha=0.89$; Registration $\alpha=0.76$; Reassessment $\alpha=0.81$, and Implementation of pharmacological interventions $\alpha=0.70$. The highest mean values of the overall scores are related to pharmacological interventions $(3.13 \pm 0.60)$.

Conclusion: The scale is a reliable and valid tool for assessing the pain management practices of Portuguese nurses. Most nurses apply pharmacological interventions to manage the pain endured by patients.
\end{abstract}

Keywords: pain; pain management; nursing care; psychometrics

\section{Resumo}

Enquadramento: A dor é gerida de forma ineficaz pelos enfermeiros, em parte pela inexistência de um instrumento capaz de medir e monitorizar esta prática.

Objetivo: Avaliar as propriedades psicométricas da Escala de Práticas de Enfermagem na Gestão da Dor.

Metodologia: Este estudo descritivo-correlacional avaliou a consistência interna através do alfa de Cronbach e a análise fatorial confirmatória através da matriz de covariâncias - algoritmo da máxima verosimilhança.

Resultados: Foram incluídos 260 enfermeiros com uma média de 35,42 anos, sendo 78,5\% mulheres. Após o refinamento da escala, a consistência interna global foi de $\alpha=0,95$ e por fatores de: Avaliaçáo inicial $\alpha=0,85$; Planeamento $\alpha=0,76$; Execução de intervençóes não farmacológicas $\alpha=0,80$; Ensino à pessoa com dor $\alpha=$ 0,89 ; Registo $\alpha=0,76$; Reavaliação $\alpha=0,81$, e Execuçáo de intervençôes farmacológicas $\alpha=0,70$. Os valores médios mais elevados dos scores globais são relativos às intervençóes farmacológicas $(3,13 \pm 0,60)$.

Conclusão: A escala é fiável e válida na avaliação das práticas de gestão da dor em enfermeiros portugueses. Os enfermeiros aplicam maioritariamente as intervençóes farmacológicas para gerir a dor dos utentes.

Palavras-chave: dor; manejo da dor; cuidados de enfermagem; psicometria

\footnotetext{
*MSc., RN, Centro Hospitalar e Universitário de Coimbra, EPE, Emergency Department, 3000-075, Coimbra, Portugal [catinhantonio@gmail.com]. (D) https://orcid.org/0000-00018646-1913. Contribution to the article: literature review and article writing; data discussion; revision for the final paper.

**MSc., RN, Centro Hospitalar e Universitário de Coimbra, EPE, Rheumatology Department, Portugal. Health Sciences Research Unit (UICISA: E), Nursing School of Coimbra (ESEnfC), Portugal [eifsantos87@gmail.com]. (10 https://orcid.org/0000-0003-0557-2377. Contribution to the article: literature review and. to the article: literature review and article witing, lata trean for the final paper. Address for correspondence: Serviço de Reumatologia, Consulta Externa,
Centro Hospitalar e Universitário de Coimbra, EPE, Avenida Dr. Bissaya Barreto, 3000-075 Coimbra, Portugal.

Coimbra, Portugal.
$* * *$ Ph.D., Lecturer, Polytechnic Institute of Viseu, School of Health, CI\&DETS, UNICISA-E, CIEC, 3500-843, Viseu, Portugal [iolmadalena2@gmail.com]. (1) https://orcid.org/0000-00030710-9220. Contribution to the article: literature review and article writing; data discussion; revision for final paper.

***:Ph.D., Lecturer, Polytechnic Institute of Viseu, School of Health, CI\&DETS, UNICISA-E, CIEC, 3500-843, Viseu, Portugal [jduarte@essvipv.pt]. (10) https://orcid.org/0000-0001-70828012. Contribution to the article: data treatment, data discussion, and revision for final paper:
}

\section{Resumen}

Marco contextual: Los enfermeros gestionan de manera ineficaz el dolor, en parte debido a que no disponen de un instrumento capaz de medir y monitorear esta práctica.

Objetivo: Evaluar las propiedades psicométricas de la Escala de Prácticas de Enfermería en la Gestión del Dolor.

Metodología: Este estudio descriptivo-correlacional evaluó la consistencia interna a través del alfa de Cronbach y el análisis factorial confirmatorio a través de la matriz de covarianza - algoritmo de máxima verosimilitud.

Resultados: Se incluyeron 260 enfermeros con una edad media de 35,42 años, de los cuales el 78,5\% eran mujeres. Tras el perfeccionamiento de la escala, la consistencia interna global fue $\alpha=0,95$ y por factores de: Evaluación inicial $\alpha=$ 0,85 ; Planificación $\alpha=0,76$; Ejecución de intervenciones no farmacológicas $\alpha=0,80$; Enseñanza a la persona con dolor $\alpha$ $=0,89$; Registro $\alpha=0,76$; Reevaluación $\alpha=0,81$, y Ejecución de intervenciones farmacológicas $\alpha=0,70$. Los valores medios más altos de las puntuaciones globales están relacionados con las intervenciones farmacológicas $(3,13 \pm 0,60)$. Conclusión: La escala es fiable y válida en la evaluación de las prácticas de la gestión del dolor en enfermeros portugueses. La mayoría de los enfermeros aplican intervenciones farmacológicas para controlar el dolor en los pacientes

Palabras clave: dolor; manejo del dolor; atención de enfermería; psicometría 


\section{Introduction}

Pain is an universal experience of every human being since we all endure pain at some point in life (Larner, 2014). Despite this inevitability, not all people stand pain and refer to it in the same way, the universality of painful experience thus encompassing the multiple facets of human subjectivity (Larner, 2014). For this reason, and primarily due to its subjectivity, it is assumed that the most reliable method for measuring pain should be self-report, enabling the patient himself to assess and characterize his/her pain (Barr et al., 2013).

Due to the high prevalence of pain, it is necessary to implement measures for its management, and it is essential to adequately train the professionals who deliver care to the person with pain (Hong \& Lee, 2014; Kizza, Muliira, Kohi, \& Nabirye, 2016; Andersson et al., 2017). However, many patients still have their pain managed inefficiently, mainly due to non-compliance with the recommendations for pain management practices and even to inadequate training (Hong \& Lee, 2014; Kizza et al., 2016; Andersson et al., 2017).

As pain has not been given the right priority and health professionals are still unable to manage it well, the purpose of this study is all the more crucial. The study sought to assess the psychometric properties, namely the factor structure and internal consistency of the Nursing Care Scale for Pain Management (António, 2017). This scale is a self-administered instrument consisting of 68 items. It was developed in Portugal in 2017 and includes a two-part questionnaire, the first consisting of social-demographic questions and the second part is the scale per se. It is used for measuring and monitoring such practices in view of implementing measures for improving the outcomes.

\section{Background}

Pain has different presentations, and it can disappear quickly, last for months, years, or become recurrent. It can disrupt a person's daily routine slightly or make one's lifestyle completely unviable (Ribeiro, 2013). In this sense, pain is fundamentally a complex and multidimensional process, an experience that involves physical, psychological, emotional, and social-cultural factors (Ribeiro,
2013; Glowacki, 2015).

Pain is a highly prevalent phenomenon, and studies have shown that it is common among hospitalized patients, mainly due to lack of adherence to pain management recommendations and even to inadequate training of health professionals who manage the person with pain (Hong \& Lee, 2014; Kizza et al., 2016; Andersson et al., 2017). Therefore, it is urgent to improve pain management, which involves not only the development of new drugs or technologies but also the use and enhancement of existing knowledge of health professionals by the institutions (Kizza et al., 2016; Andersson et al., 2017).

Nurses' role in pain management is crucial and includes its assessment, the use of pharmacological and non-pharmacological means suitable for each case. Examples of non-drug measures include the use of heat and cold, distraction, massage, relaxation, promotion of comfort, therapeutic touch, among others (Drake \& Williams, 2017), It is recommended that pain be systematically monitored to ensure proper pain management. However, nurses do not always assess it adequately, as they base themselves on personal pain estimates (Drake \& Williams, 2017). Consequently, some studies assess nurses' level of knowledge about the principles of pain management and assessment only as adequate (Kizza et al., 2016). Even so, several studies have shown that the adoption of pain management guidelines and continuous training have improved pain management and assessment practices (Hong \& Lee, 2014; Kizza et al., 2016; Andersson et al., 2017).

Resorting to an instrument for measuring and monitoring such practices will help make reality more objective and implement targeted strategies that can minimize pain.

\section{Research question}

Does the Nursing Care Scale for Pain Management have adequate psychometric properties for assessing such practice?

\section{Methodology}

A psychometric descriptive-correlational study was conducted, based on cross-sectional data collection in a non-probabilistic convenience 
sample in two adult emergency departments in central Portugal. Only nurses who worked in this context and did not hold management positions were included.

All participants signed the informed consent form before performing any procedure. The approval was obtained through the Opinion of the Ethics Committee of the Health Sciences Research Unit of the Nursing School of Coimbra (No. 16205/2013) and the Opinion of the Tondela Viseu Hospital Center (No. 02/05/2018).

\section{Data collection tool}

The Nursing Care Scale for Pain Management is a self-administered instrument composed of 68 items, divided into two parts: the first part includes questions about the social and professional status (age, gender, academic qualifications, length of professional experience, length of professional practice in the emergency department); the second part includes questions for assessing nursing practices implemented for pain management in the following domains: initial assessment (items 1-28), planning (items 3137), implementation of pharmacological (items 38-40) and non-pharmacological (items 41-52) interventions, reassessment (items 53-54; 57-60), recording (items 29-30; 55-56), and educating the person with pain (items $61-68$ ). These items are assessed using a Likert scale that measures frequency with the following scores: (0) I don't know/no opinion; (1) never; (2) rarely; (3) often; (4) always (António, 2017).

The process of constructing this scale was based on a semantic and content analysis by a panel of experts with subsequent implementation of a pre-test (António, 2017).

\section{Statistical techniques}

Descriptive and correlational analyses and an internal consistency study were performed using IBM SPSS Statistics software, version 24.0, by determining Pearson's correlation coefficient and Cronbach's alpha. To analyze the internal consistency, the following reference values were considered: >0.9 very good; 0.8-0.9 good; 0.7-0.8 average; 0.6-0.7 reasonable; 0.5-0.6 poor; $<0.5$ unacceptable (Marôco, 2014). The Pearson's correlation coefficient assumed the following asso- ciations: $r<0.2$ very low; $0.2 \leq r \leq 0.39$ low; 0.4 $\leq r \leq 0.69$ moderate; $0.7 \leq r \leq 0.89$ high; $0.9 \leq r$ $\leq 1$ very high (Marôco, 2014).

The AMOS V.24.0 software (IBM SPSS, Chicago, Illinois, USA) was used for the confirmatory factor analysis, and the algorithm of maximum likelihood provided the matrix of covariances. Before performing this analysis, the assumptions of normality were confirmed through the asymmetry coefficients, kurtosis, and the multivariate coefficient of Mardia, whose reference values are $\leq 3.0$; $\leq 7.0$ and 5.0, respectively (Hair, Black, Babin, Anderson, \& Tatham, 2005; Kline, 2005; Marôco, 2014).

As recommended, different global adjustment indices were used, namely the Chi-square to Degrees of Freedom ratio $\left(\mathrm{x}^{2} / \mathrm{gl}\right)$, Goodness-of-Fit Index (GFI), Comparative-of-Fit Index (CFI), Root Mean Square Error of Approximation (RMSEA), Root Mean Square Residual (RMR), and Standardized Root Mean Square Residual (SRMR). A good model adjustment is assumed when: $\mathrm{x}^{2} /$ $\mathrm{gl}<3$; GFI and CFI values > 0.90; RMSEA, RMR and SRMR values $<0.06$ are considered ideal, although scores between 0.08 and 0.10 are acceptable. To analyze the quality of the local adjustment of the model, the lambda coefficients $(\lambda)$ and the individual reliability of the items $\left(r^{2}\right)$ were considered, whose reference values are 0.50 and 0.25, respectively (Byrne, 2000; Marôco, 2014).

\section{Results}

This study involved 260 nurses, between the ages of 22 and 59 years and a mean age of 35.42 years (Standard deviation - SD \pm 7.62 years), mostly female $(78.5 \%), 75.8 \%$ had undergraduate degrees, and $70.7 \%$ were undergoing post-graduate studies. They had on average 12.21 years of professional experience ( $S D \pm 7.76$ years), and the length of experience in the emergency department was 9.21 years ( $S D \pm 6.89$ years).

The analysis of the reliability of the Nursing Care Scale for Pain Management revealed that the means of the items ranged from 1.85 (item 45) to 3.38 (item 6). The study of internal consistency by item and the overall value $(\alpha=0.95$; Table 1$)$ was considered very good. 
Table 1

Internal consistency of the Nursing Care Scale for Pain Management

\begin{tabular}{|c|c|c|c|c|}
\hline $\begin{array}{l}\text { Item } \\
\text { No. }\end{array}$ & Items & Mean & $\begin{array}{l}\text { Standard } \\
\text { deviation }\end{array}$ & $\alpha$ w/out item \\
\hline 1 & I realize that the individual is the best assessor of his/her pain & 3.12 & 0.74 & 0.95 \\
\hline 2 & I always believe in the person with pain & 2.99 & 0.77 & 0.95 \\
\hline 3 & I perform the physical examination while taking the pain history & 2.73 & 0.98 & 0.95 \\
\hline 4 & I characterize pain according to duration & 3.08 & 0.78 & 0.95 \\
\hline 5 & I characterize pain according to frequency & 3.08 & 0.82 & 0.95 \\
\hline 6 & I characterize pain according to location & 3.38 & 0.59 & 0.95 \\
\hline 7 & I characterize pain according to intensity & 3.33 & 0.71 & 0.95 \\
\hline 8 & I characterize pain according to quality & 2.68 & 1.12 & 0.95 \\
\hline 9 & $\begin{array}{l}\text { I inquire about the person's usual ways of communicating/ } \\
\text { expressing pain }\end{array}$ & 2.58 & 1.08 & 0.95 \\
\hline 10 & I consider pain relief and/or aggravation factors & 3.15 & 0.68 & 0.95 \\
\hline 11 & I ask about coping strategies in pain management & 2.39 & 1.10 & 0.95 \\
\hline 12 & I ask the person about the impact of pain on daily life activities & 2.77 & 0.89 & 0.95 \\
\hline 13 & I explore a person’s knowledge of pain & 2.18 & 1.08 & 0.95 \\
\hline 14 & I assess the emotional impact of pain & 2.50 & 0.97 & 0.95 \\
\hline 15 & I assess the social-economic impact of pain & 1.97 & 0.95 & 0.95 \\
\hline 16 & I assess the spiritual impact of pain & 1.93 & 0.98 & 0.95 \\
\hline 17 & I identify symptoms associated with pain & 3.07 & 0.70 & 0.95 \\
\hline 18 & $\begin{array}{l}\text { I adapt the pain assessment instrument to the person's charac- } \\
\text { teristics }\end{array}$ & 2.92 & 1.05 & 0.95 \\
\hline 19 & I monitor pain using pain scales & 3.21 & 0.90 & 0.95 \\
\hline 20 & $\begin{array}{l}\text { I assess the intensity of pain by giving preference to self-assess- } \\
\text { ment instruments }\end{array}$ & 2.66 & 1.10 & 0.95 \\
\hline 21 & $\begin{array}{l}\text { I assess pain in people with verbal communication disability } \\
\text { and/or cognitive changes, based on physiological and behavior- } \\
\text { al indicators, using hetero-assessment scales }\end{array}$ & 2.75 & 1.06 & 0.95 \\
\hline 22 & $\begin{array}{l}\text { I regularly and systematically assess the intensity of pain, as for } \\
\text { assessing other vital signs }\end{array}$ & 3.19 & 2.65 & 0.96 \\
\hline 23 & Alongside pain assessment, I measure heart rate & 2.90 & 0.92 & 0.95 \\
\hline 24 & Alongside pain assessment, I measure breathing rate & 2.62 & 1.03 & 0.95 \\
\hline 25 & Alongside pain assessment, I measure blood pressure & 2.64 & 1.05 & 0.95 \\
\hline 26 & $\begin{array}{l}\text { I maintain the same pain assessment scale for all assessments } \\
\text { of the same person, except if the clinical situation justifies its } \\
\text { change }\end{array}$ & 2.88 & 1.09 & 0.95 \\
\hline 27 & $\begin{array}{l}\text { I adapt the frequency of pain assessment to a person's clinical } \\
\text { condition }\end{array}$ & 3.04 & 0.88 & 0.95 \\
\hline 28 & I assess pain at least once per shift & 3.03 & 1.03 & 0.95 \\
\hline 29 & $\begin{array}{l}\text { I record the intensity of pain on the vital signs' app available in } \\
\text { the software }\end{array}$ & 2.95 & 1.03 & 0.95 \\
\hline 30 & I record pain characteristics and history in nursing notes & 2.74 & 0.95 & 0.95 \\
\hline 31 & I identify pain diagnosis & 2.18 & 1.13 & 0.95 \\
\hline 32 & I plan interventions for pain management & 2.66 & 1.08 & 0.95 \\
\hline
\end{tabular}


33 I use the flowchart (e.g., headache, abdominal pain, chest pain) to plan pain management interventions

I consider the discriminator (e.g., moderate, severe, precordial pain) when planning pain management interventions

I actively collaborate with the rest of the multidisciplinary team to set up a pain management intervention plan

I involve the person in setting up the treatment plan and adjusting it

I adjust the treatment plan to the reassessment results and the available resources

I know which analgesic drugs were prescribed (indications, contraindications, side effects, drug interactions)

39 I monitor the safety of analgesic therapy

I prevent and control pain arising from nursing care and diagnostic or therapeutic procedures

I am familiar with non-drug pain control methods (indications, contraindications, side effects)

I use non-pharmacological interventions to complement pharmacological therapy

43 I apply heat and cold, where appropriate, to control pain

44 I use distraction, where appropriate, to control pain

45 I use guided imagination, where appropriate, to control pain

47 I use relaxation, where appropriate, to control pain

49 I position the person adequately to control pain

50 I foster comfort to control pain

51 I foster therapeutic touch to control pain

I execute or maintain physical restraint to prevent alignment in trauma situations

I monitor the effectiveness of implemented pharmacological interventions

I monitor the effectiveness of implemented non-pharmacological interventions

I record systematically pharmacological interventions, their effects, and changes in the therapeutic plan

I systematically record non-pharmacological interventions, their effects, and changes to the therapeutic plan

I schedule in the computer system subsequent reassessments after intervention for pain management

58 When reassessing pain, I compare with the previous value

I report the outcomes of the pain assessment/intervention to

I report the outcomes of the pain assessment/intervention to other teams on the transfer of the patient to another unit

61 I assess the person's knowledge of pain self-control 
I assess the person's knowledge of pharmacological strategies for pain control

I assess the person's knowledge of non-pharmacological strategies for pain control

I teach the person pharmacological strategies and for pain control

66

I teach the person non-pharmacological strategies and for pain control

67

I educate the person about the collateral effects of analgesic therapy

I educate the person about the need to give health professionals an early indication of changes in pain (aggravation, change in pattern, new sources and types, side effects of analgesic therapy)
2.35

2.33

1.01

2.56

0.97

0.95

2.54

0.94

0.95

2.75

0.85

0.95

2.97

0.77

0.95

\section{Confirmatory factor analysis}

At first, item trajectories for the respective factors, the corresponding critical ratios and the lambda coefficient of the hepta-factorial solution were analyzed, and all ratios were found to be statistically significant $(p<0.05)$. However, it was found that several items had saturations below 0.50 and individual reliability was below 0.25 , negatively affecting the overall adjustment indices, so it was recommended to take out these items during the model refinement process (Marôco, 2014). Consequently, 24 items were eliminated.

It was also found that the correlational values between the factors were high, and a hierarchical structure with a $2^{\text {nd }}$ order factor was thus proposed (Figure 1).

The lowest correlation with the overall factor was observed in factor 7 , which explains $45 \%$, and the highest with factor 6 , with a variability of $96 \%$ (Figure 1).

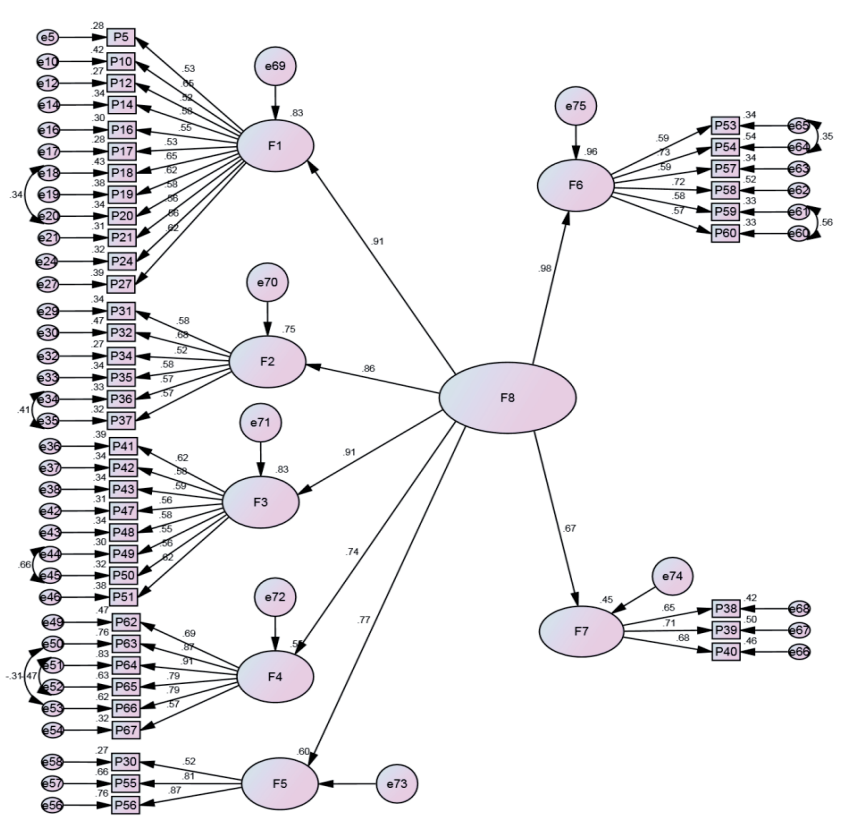

Figure 1. Second-order model. 
Table 2 provides an overview of the global adjustment indices.

Table 2

Adjustment quality indices for all models

\begin{tabular}{lcccccc}
\hline Model & $\mathrm{x}^{2} / \mathrm{gl}$ & GFI & CFI & RMSEA & RMR & SRMR \\
\hline Initial model & 2.70 & 0.58 & 0.55 & 0.08 & 0.07 & 0.07 \\
Model with modification indices & 2.98 & 0.63 & 0.66 & 0.08 & 0.07 & 0.07 \\
Model with deleted items & 2.12 & 0.75 & 0.82 & 0.06 & 0.06 & 0.06 \\
Second-order model & 2.18 & 0.74 & 0.81 & 0.06 & 0.06 & 0.06 \\
\hline
\end{tabular}

Note. $\mathrm{x}^{2} / \mathrm{gl}$ - Chi-square / Degrees of Freedom; GFI - Goodness-of-Fit Index; CFI - Comparative-of-Fit Index; RMSEA - Root Mean Square Error of Approximation; RMR - Root Mean Square Residual; SRMR - Standardized Root Mean Square Residual.

It should be noted that, in the process of refining the model, the adjustment indices improved and recorded adequate values, except the GFI, which proved to be inadequate, and the CFI with poor adjustment.
It was also possible to analyze its factor structure and the consistency by factors based on the final version of the scale (Table 3 ).

Table 3

Internal consistency by factors

\begin{tabular}{|c|c|c|c|c|c|}
\hline Items & Mean & $\begin{array}{l}\text { Standard } \\
\text { deviation }\end{array}$ & Total $r /$ item & $r^{2}$ & $\alpha \mathrm{w} /$ out item \\
\hline Initial assessment & & & & & 0.85 \\
\hline 5 & 3.08 & 0.82 & 0.47 & 0.32 & 0.85 \\
\hline 10 & 3.15 & 0.68 & 0.57 & 0.42 & 0.84 \\
\hline 12 & 2.77 & 0.89 & 0.46 & 0.28 & 0.85 \\
\hline 14 & 2.50 & 0.97 & 0.51 & 0.33 & 0.84 \\
\hline 16 & 1.93 & 0.98 & 0.51 & 0.32 & 0.84 \\
\hline 17 & 3.07 & 0.70 & 0.45 & 0.31 & 0.85 \\
\hline 18 & 2.92 & 1.05 & 0.64 & 0.50 & 0.83 \\
\hline 19 & 3.21 & 0.90 & 0.60 & 0.40 & 0.84 \\
\hline 20 & 2.66 & 1.10 & 0.57 & 0.42 & 0.84 \\
\hline 21 & 2.75 & 1.06 & 0.53 & 0.37 & 0.84 \\
\hline 24 & 2.62 & 1.03 & 0.51 & 0.29 & 0.84 \\
\hline 27 & 3.04 & 0.88 & 0.57 & 0.37 & 0.84 \\
\hline Planning & & & & & 0.76 \\
\hline 31 & 2.18 & 1.13 & 0.39 & 0.18 & 0.76 \\
\hline 32 & 2.66 & 1.08 & 0.59 & 0.38 & 0.70 \\
\hline 34 & 2.70 & 1.10 & 0.46 & 0.28 & 0.74 \\
\hline 35 & 2.83 & 0.94 & 0.51 & 0.30 & 0.73 \\
\hline 36 & 2.42 & 1.16 & 0.54 & 0.42 & 0.72 \\
\hline 37 & 2.68 & 1.05 & 0.54 & 0.41 & 0.72 \\
\hline
\end{tabular}




\begin{tabular}{|c|c|c|c|c|c|}
\hline $\begin{array}{l}\text { Implementation of non-pharma- } \\
\text { cological interventions }\end{array}$ & & & & & 0.80 \\
\hline 41 & 2.76 & 1.04 & 0.56 & 0.35 & 0.77 \\
\hline 42 & 2.48 & 1.06 & 0.51 & 0.32 & 0.78 \\
\hline 43 & 2.66 & 0.88 & 0.51 & 0.32 & 0.78 \\
\hline 47 & 1.97 & 0.97 & 0.46 & 0.31 & 0.78 \\
\hline 48 & 2.40 & 0.95 & 0.54 & 0.34 & 0.77 \\
\hline 49 & 3.14 & 0.62 & 0.54 & 0.62 & 0.78 \\
\hline 50 & 3.15 & 0.67 & 0.51 & 0.60 & 0.78 \\
\hline 51 & 2.60 & 1.01 & 0.52 & 0.28 & 0.77 \\
\hline Education of the person with pain & & & & & 0.89 \\
\hline 62 & 2.20 & 1.06 & 0.65 & 0.45 & 0.88 \\
\hline 63 & 2.35 & 1.07 & 0.78 & 0.71 & 0.85 \\
\hline 64 & 2.33 & 1.01 & 0.83 & 0.76 & 0.85 \\
\hline 65 & 2.56 & 0.97 & 0.72 & 0.58 & 0.86 \\
\hline 66 & 2.54 & 0.94 & 0.70 & 0.58 & 0.87 \\
\hline 67 & 2.75 & 0.85 & 0.54 & 0.31 & 0.89 \\
\hline Recording & & & & & 0.76 \\
\hline 30 & 2.74 & 0.95 & 0.45 & 0.21 & 0.83 \\
\hline 55 & 2.70 & 1.14 & 0.66 & 0.51 & 0.61 \\
\hline 56 & 2.48 & 1.09 & 0.71 & 0.54 & 0.55 \\
\hline Reassessment & & & & & 0.81 \\
\hline 53 & 2.98 & 0.91 & 0.50 & 0.40 & 0.80 \\
\hline 54 & 2.69 & 1.02 & 0.63 & 0.53 & 0.77 \\
\hline 57 & 2.22 & 1.09 & 0.50 & 0.30 & 0.80 \\
\hline 58 & 2.82 & 1.05 & 0.62 & 0.44 & 0.77 \\
\hline 59 & 2.92 & 0.93 & 0.61 & 0.52 & 0.78 \\
\hline 60 & 2.73 & 1.07 & 0.61 & 0.53 & 0.78 \\
\hline $\begin{array}{l}\text { Implementation of pharmacological } \\
\text { interventions }\end{array}$ & & & & & 0.70 \\
\hline 38 & 3.27 & 0.68 & 0.54 & 0.30 & 0.58 \\
\hline 39 & 3.28 & 0.64 & 0.54 & 0.31 & 0.59 \\
\hline 40 & 2.87 & 0.93 & 0.51 & 0.26 & 0.66 \\
\hline
\end{tabular}

For the Initial assessment factor, the most favorable item was item 19, while item 16 was the least favorable. The Cronbach's alpha coefficients obtained in the 12 items ranged from 0.83 in item 18 to 0.85 in items 5,12 , and 17 , indicating a good consistency, with a overall alpha of 0.85 . The highest correlation value was found in item $18(r=0.64)$, with variability of $50.9 \%$, and the one with the lowest correlation was item $17(r=0.45)$, with $32.0 \%$ explained variance.
Concerning the Planning factor, in average terms, the most favorable item was 35 , and the least favorable item was 31 , although the results suggest that they were well centered, given the mean values and the respective standard deviations obtained. The coefficients of the six items of this dimension ranged from $\alpha=0.76$ in item 31 to $\alpha=0.70$ in item 32, indicating a reasonable internal consistency, with an overall alpha of 0.76 . The highest correlation value was found in item $32(r=0.59)$, and item 31 
had the lowest correlation $(r=0.39), 38.6 \%$ and $18.2 \%$ variance.

Regarding the Implementation of non-pharmacological interventions factor, the highest mean was recorded in item 50, and item 47 had the lowest. The coefficients ranged from $\alpha=0.77$ in item 41 and $\alpha=0.78$ in item 47 , with an overall coefficient of $\alpha=0.80$, which revealed a good internal consistency. The highest correlational value obtained was in item $41(r=0.56)$ and the lowest in item $47(r=$ 0.46 ), with percentages of explained variance of $35.9 \%$ and $31.0 \%$, respectively.

Under Education of the person with pain, the most favorable item was 67 , and 62 was the least favorable item. The coefficients of the six items ranged from $\alpha=0.76$ in item 64 to $\alpha$ $=0.89$ in item 67 , suggesting good internal consistency, with an overall alpha of 0.89 . The highest correlation value was found in item 64 $(r=0.83)$, with variability of $76.5 \%$, and the one with the lowest correlation was item $67(r$ $=0.54$ ), with $31.1 \%$ explained variance.

Regarding the Recording factor, item 30 had the highest mean, while the lowest was item 56. The coefficients ranged from $\alpha=0.55$ in item 56 and $\alpha=0.83$ in item 30, with an overall coefficient of $\alpha=0.76$, which revealed a good and reasonable internal consistency. The highest correlational value obtained was in item $56(r=0.71)$ and the lowest in item 30 $(r=0.45)$, with $54.5 \%$ and $21.3 \%$ explained variance, respectively.

Concerning Reassessment, in average terms, the most favorable item was 53, and 57 was the least favorable item. The coefficients of the six items of this dimension ranged from $\alpha=0.77$ in item 54 to $\alpha=0.80$ in item 57 , indicating a reasonable internal consistency, with an overall alpha of 0.81 . The highest correlation value was found in item $54(r=0.63)$, and item $57 \mathrm{had}$ the lowest correlation $(r=0.50)$, with $53.0 \%$ and $30.7 \%$ variance.

Lastly, for the Implementation of pharmacological interventions factor, according to the mean values, the most favorable item was 39, and item 40 was the least favorable. The coefficients of the three items ranging from $\alpha=0.58$ for item 38 to $\alpha=0.66$ for item 40 suggest good internal consistency, with an overall alpha of 0.70 . The highest correlation value was found in item $39(r=0.54)$, with a variability of $31.0 \%$, and item 40 had the lowest correlation $(r=$ 0.51 ), with $26.2 \%$ explained variance.

\section{Pain management practices}

The results regarding the mean values of the overall score and factors of the Nursing Care Scale for Pain Management suggest that the highest mean value was that of Implementation of pharmacological interventions (Mean - $M=$ $3.13 \pm 0.60)$, followed by the Initial assessment $(M=2.80 \pm 0.58)$, Reassessment $(M=2.72 \pm$ $0.73)$, Implementation of non-pharmacological interventions $(M=2.64 \pm 0.59)$, Recording $(M$ $=2.64 \pm 0.88)$, Planning $(M=2.57 \pm 0.73)$, and Educating the person with pain $(M=2.45$ \pm 0.79 ) factors.

The statistics on pain management practices by gender revealed that participants of both genders had the same mean value for Planning $(M=2.66)$, Educating the person with pain $(M=2.50)$, Reassessment $(M=2.83)$ and Implementation of pharmacological interventions $(M=3.00)$. However, female nurses differ from male nurses, as they present better pain management practices under Initial assessment $(M=2.91$ vs. $M=2.58)$, Implementation of non-pharmacological interventions $(M=2.75$ vs. $M=2.50)$, and Recording $(M=2.83$ vs. $M=2.66)$.

\section{Discussion}

This study on the validation of the psychometric properties of the Nursing Care Scale for Pain Management focused on the validity, content, and criteria of the construct, and sought to enhance further its validity.

The construct validity seeks to ascertain whether the instrument measures what it intends to measure and is accepted since the tests in its favor are superior to the opposing tests (Cunha et al., 2018).

Internal consistency was considered very good, according to an overall score of $\alpha=0.95$. The internal consistency of the 68 final items that make up the scale ranged between reasonable and good consistency. The adjustment of the final model ( 2 nd order) showed adequate values in four of the six indices, except the GFI and CFI. Therefore, it is recommended to replicate 
the psychometric study in larger samples to obtain higher sensitivity. Overall, the scale proves to be reliable and valid for assessing the pain management practices of Portuguese nurses.

The results of applying the scale also showed that, of all pain management practices, nurses carry out mostly pharmacological interventions. This finding, which several studies sustain, is mainly because this is an interdisciplinary intervention and that there are difficulties in implementing other pain management measures, such as non-pharmacological interventions and pain assessments (which include initial assessment, planning, education, recording, and reassessment; Becker et al., 2017; Dequeker, Van Lancker, \& Van Hecke, 2018; Gan et al., 2018).

Pain assessment is recognized in the scientific literature as a challenge, pain education and intervention planning being the most neglected areas in clinical practice (Araujo \& Romero, 2015; Medrzycka-Dabrowka, Dąbrowski, Gutysz-Wojnicka, Gawroska-Krzemińska, \& Ozga, 2017). The results of this study also corroborate these findings since the overall mean scores for pain education and planning were the lowest. In addition, the difficulties and barriers imposed by the specific context of emergency departments are acknowledged, such as lack of time, overwork, and reluctance to prescribe and implement pharmacological measures due to an inadequate assessment of the painful experience (Pretorius, Searle, \& Marshall, 2015). This study also found that Recording had lower mean scores, which may compromise the following process of pain monitoring and reassessment, invariably resulting in ineffective pain management. Female nurses showed better pain management practices than male nurses. It should be noted that this study has some limitations. First, although the size of the sample is satisfactory, the scale has many items even after it was refined. As previously mentioned, 24 items were eliminated, but 44 items were retained. However, even if the sample were to be increased, the results would remain similar because bootstrap re-sampling simulations $(n=2000)$ were performed, and the models presented did not change significantly. Finally, despite the fact that the sample is composed of two emergency departments, this does not invalidate the importance of conducting a broader multicenter study or additional studies for other more specific contexts in the future.

\section{Conclusion}

The uniqueness of pain and the numerous factors affecting it require it to be managed using the appropriate practices, which often materialize with the implementation of continuous pain assessment improvement programs. However, the lack of instruments for measuring this construct means that this reality is hardly ever studied. Therefore, the Nursing Care Scale for Pain Management was developed, paving the way for this psychometric study, which revealed very good internal consistency, demonstrating that the scale is a reliable and valid means to assess pain management practices of Portuguese emergency department nurses.

Of all pain management practices, nurses implement mostly pharmacological interventions. Female nurses showed better pain management practices than male nurses.

As for the impact on practice, and because nurses mostly apply the pharmacological interventions to manage pain, while "devaluing" other practices, it is necessary to plan continuous training in and audit of such alternative practices. This scale can make a valid contribution to optimizing monitoring.

Finally, and based on the implications for research, it is essential to strengthen the current evidence and, although important psychometric properties have been assessed, studies in the future should focus on the properties that have not received attention, namely the temporal stability of the scale due to its potential use for monitoring practices.

\section{Funding source}

This study was funded by the Portuguese $\mathrm{Na}$ tional Funding Agency for Science, Research and Technology and by CI \& DETS, IPV.

\section{References}

Andersson, V., Bergman, S., Henoch, I., Ene Kerstin, W., Otterström-Rydberg, E., Simonsson, H., \& Ahlberg, K. (2017). Pain and pain management in hospitalized patients before and after an intervention. Scandina- 
vian Journal of Pain, 15(1), 22-29. doi:10.1016/j. sjpain.2016.11.006

António, C. A. (2017). Gestão da dor no serviço de urgência: Práticas dos enfermeiros (Master's Dissertation). Escola Superior de Enfermagem de Coimbra, Portugal. Retrieved from http://web.esenfc.pt/?url=MB7fbUHQ

Araujo, L. C., \& Romero, B. (2015). Pain: Evaluation of the fifth vital sign: A theoretical reflection. Revista Dor, 16(4), 291-296. doi:10.5935/1806-0013.20150060

Barr, J., Fraser, G. L., Puntillo, K., Ely, E. W., Gelinas, C., Dasta, J. F., ... Jaeschke, R. (2013). Clinical practice guidelines for the management of pain, agitation, and delirium in adult patients in the intensive care unit. Critical Care Medicine, 41(1), 263-306. doi:10.1097/ CCM.0b013e3182783b72

Becker, W. C., Dorflinger, L., Edmond, S. N., Islam, L., Heapy, A. A., \& Fraenkel, L. (2017). Barriers and facilitators to use of non-pharmacological treatments in chronic pain. BMC Family Practice, 18(1), 41. doi:10.1186/s12875-017-0608-2

Byrne, B. M. (2000). Structural equation modeling with AMOS: Basic concepts, applications, and programing. Mahwah, NJ: Lawrence Erlbaum Associates.

Cunha, M., Duarte, J., Cardoso, A., Ramos, A., Quintais, D., Monteiro, R., ... Almeida, V. (2018). Inventário habilidades do cuidador: Estrutura fatorial numa amostra de participantes portugueses. Millenium, 2(6), 41-55. doi:10.29352/mill0206.04.00164

Dequeker, S., Van Lancker, A., \& Van Hecke, A. (2018). Hospitalized patients' vs. nurses' assessments of pain intensity and barriers to pain management. Journal of Advanced Nursing, 74(1), 160-171. doi:10.1111/ jan. 13395

Drake, G., \& Williams, A. C. (2017). Nursing education interventions for managing acute pain in hospital settings: A systematic review of clinical outcomes and teaching methods. Pain Management Nursing, 18(1), 3-15. doi:10.1016/j.pmn.2016.11.001

Gan, T. J., Epstein, R. S., Leone-Perkins, M. L., Salimi, T., Iqbal, S. U., \& Whang, P. G. (2018). Practice patterns and treatment challenges in acute postoperative pain management: A survey of practicing physicians. Pain and Therapy, 7(2), 205-216. doi:10.1007/s40122018-0106-9

Glowacki, D. (2015). Effective pain management and improvements in patients' outcomes and satisfaction. Critical Care Nurse, 35(3), 33-41. doi:10.4037/ $\operatorname{ccn} 2015440$

Hair, J., Black, W. C., Babin, B., Anderson, R. E., \& Tatham, R. (2005). Multivariate data analyses (6th ed.). New York, NY: Prentice-Hall.

Hong, S.-J., \& Lee, E. (2014). Effect of evidence-based postoperative pain guidelines via web for patients undergoing abdominal surgery in South Korea. Asian Nursing Research, 8(2), 135-142. doi:10.1016/j. anr.2014.05.005

Kizza, I. B., Muliira, J. K., Kohi, T. W., \& Nabirye, R. C. (2016). Nurses' knowledge of the principles of acute pain assessment in critically ill adult patients who are able to self-report. International Journal of Africa Nursing Sciences, 4, 20-27. doi:10.1016/j. ijans.2016.02.001

Kline, R. B. (2005). Principles and practice of structural equation modeling. New York, NY: The Guilford Press.

Larner, D. (2014). Chronic pain transition: A concept analysis. Pain Management Nursing, 15(3), 707-717. doi:10.1016/j.pmn.2013.04.003

Marôco, J. (2014). Análise estatística com o SPSS statistics. Pero Pinheiro, Portugal: Report Number.

Medrzycka-Dabrowka, W., Dąbrowski, S., Gutysz-Wojnicka, A., Gawroska-Krzemińska, A., \& Ozga, D. (2017). Barriers perceived by nurses in the optimal treatment of postoperative pain. Open Medicine, 12, 239-246. doi:10.1515/med-2017-0037

Pretorius, A., Searle, J., \& Marshall, B. (2015). Barriers and enablers to emergency department nurses' management of patients' pain. Pain Management Nursing, 16(3), 372-379. doi:10.1016/j.pmn.2014.08.015

Ribeiro, A. L.. (2013). A pessoa com dor crónica: Um modelo de acompanhamento de enfermagem (Master's Dissertation), Universidade Católica do Porto, Portugal. Retrieved from http://hdl.handle.net/10400.14/20108 